Received Date : 16-Jan-2015

Accepted Date : 17-Jan-2015

Article type : Editorials

\title{
Recovering the Recovering Liver Graft
}

See Ching Chan, MBBS, MS, PhD, MD, Li Shu Fan Medical Foundation Professor in Surgery,

Department of Surgery, Queen Mary Hospital, The University of Hong Kong.

Corresponding author: Professor See Ching Chan

Postal address: 102 Pok Fu Lam Road, Hong Kong, China.

Email address: seechingchan@gmail.com

Telephone no.: +85222553025

Facsimile no.: +852 28165284

Abbreviations in the order of appearance:

WIT, warm ischemic time

LDLT, living donor liver transplantation

DDLT, deceased donor liver transplantation

CIT, cold ischemic time

AST, aspartate aminotransferase

ECMO, extracorporeal membrane oxygenation

This article has been accepted for publication and undergone full peer review but has not been through the copyediting, typesetting, pagination and proofreading process, which may lead to differences between this version and the Version of Record. Please cite this article as doi: 10.1111/liv.12801

This article is protected by copyright. All rights reserved. 
MELD, Model of End-stage Liver Disease

The author has no conflict of interest.

No financial support has been received.

The shortage of liver grafts from deceased donors is universal. A deceased-donor whole liver from an otherwise healthy brain-dead donor is ideal for transplantation. This situation however is very uncommon since deceased donors often have comorbidities like hypertension, diabetes, or multiple injuries. On the occasion when a whole liver with excellent function is available for transplantation, splitting it into two grafts for two recipients is often done in order to maximize utilization.

In the real world, reaching the best compromise of liver graft utilization is the desirable practice. What constitutes a marginal yet useable liver graft? Through a Cox regression model, Feng et al. [1] identified seven donor characteristics that independently predicted an increased risk of failure of a liver graft donated by a deceased donor. Among these, donation after cardiac death had a relative risk of 1.51 (95\% confidence interval 1.19-1.91, $\mathrm{p}=0.0006)$ for graft failure. Their study nevertheless did not include in the analysis cardiac arrest in donors who were successfully resuscitated. Cardiac arrest accounts for prolonged warm ischemic time (WIT) of various degrees in brain-dead-donor organs. As ischemia is central to liver cell death, duration of warm [2] and cold [1,2] ischemia is significant in prevention of graft failure. While a high body mass index and hypernatremia of a donor are associated with a high risk of graft failure, critical care end points that reflect the normal hemodynamic, acid base, respiratory, endocrine and renal statuses of a donor are predictive of liver graft use for transplantation [3]. Thus meticulous brain-dead donor maintenance and resuscitation are important [4].

This article is protected by copyright. All rights reserved. 
Among all organs for transplantation, the liver has the strongest ability to recover from insults including ischemia. It is often the last organ to be given up for deceased donor organ transplantation. The remarkable regenerative and recovering abilities of the liver have been known for centuries, thus there is the myth of Prometheus [5]. The regenerative ability of the liver allows very major hepatectomy for cancer as well as the use of partial liver for transplantation. In the face of the shortage of deceased donor liver grafts, living donor liver transplantation (LDLT) becomes the attractive and realistic alternative to deceased donor liver transplantation (DDLT). In order to minimize the risk to living liver donors, a smallest workable size of liver is obtained for transplantation. With accumulation of experience, a living donor liver graft $30 \%$ the size of the recipient liver is acceptable, with a hospital mortality risk of $2 \%$ only [6]. Nevertheless, unlike that in DDLT, the cold ischemic time (CIT) in LDLT is often less than an hour. A WIT that is as short as possible is also aimed for. At centers employing temporary inflow control by the Pringle maneuver, warm ischemia occurs without significant graft damage [7].

In fact, temporary ischemia serves to precondition a liver graft for the hostile environment in recipients with portal hypertension and to counteract reperfusion injuries [8]. Hoyer et al. [9] compared recipients who received liver grafts from donors with cardiac arrest and recipients whose liver grafts were from donors without cardiac arrest. They found that the former group of recipients had lower peak serum aspartate aminotransferase (AST) levels. This observation was not new as another study earlier had a similar finding [10]. However, whether ischemic preconditioning of liver grafts has a protective effect is inconclusive [11]. Positive [12-15] and negative $[16,17]$ views both exist. In a French study of 165 DDLTs, 34 of the donors had a history of cardiac arrest. Their median AST level was higher (104 U/L vs. $42 \mathrm{U} / \mathrm{L}, \mathrm{p}<0.001$ ). Nonetheless, when recipients in the two groups (with donors with and without cardiac arrest) were compared, levels of serum AST on days 5 and 7 and levels of peak serum AST were similar

This article is protected by copyright. All rights reserved. 
between groups. The two groups also had comparable graft survival at 6 months ( $87 \%$ vs. 88\%) [18].

In LDLT, using a graft one third the size of a whole liver relies much on a short CIT. This policy is also adopted for DDLT at an LDLT center where CIT is slightly longer than 6 hours (median 386 min, range 242-896 min) [19]. When a liver graft from a brain-dead heart-beating deceased donor recovered from cardiac arrest is used, the duration of down time and thus the WIT must be carefully monitored. A liver graft procured from a non-heart-beating donor has a higher chance of primary non-function [20] and is more prone to diffuse ischemic biliary injury [21]. Taking this to the extreme is a model of extracorporeal membrane oxygenation (ECMO) in donors with cardiac arrest with failed resuscitation. Organs obtained from donations after cardiac arrest are subjected to prolonged WIT. In a Spanish study of ECMO, donors with cardiac arrest were placed on the ECMO circuit. Recipient survival and graft survival at one year were $82 \%$ and $70 \%$ respectively [22].

As Hoyer et al. [9] pointed out, selection of donors in their study was careful and not in a random manner. The donors with cardiac arrest were significantly younger, and their donated livers were in status $1 \mathrm{~A}(28 \%$ vs. $17.7 \%, \mathrm{p}=0.028)$. Liver grafts procured from donors with cardiac arrest are often rejected by centers and used as rescue grafts for patients in dire emergency of liver failure. Marginal liver grafts are not transplanted to good-risk patients with low Model of End-stage Liver Disease (MELD) scores but to patients who are more ill. Similar experience was reported by the aforesaid French study [18]. Schaubel et al. [23] showed that pairing of marginal liver grafts with patients with low MELD scores failed to maximize survival benefit and may deny life-saving livers to patients with high MELD scores who have a high risk of death without transplantation. This is the day-in day-out experience of LDLT in the highurgency situation in Asia [24].

This article is protected by copyright. All rights reserved. 
What has not been discussed is the continuous assessment of potential liver donors' resuscitation and liver function recovery. Donor management aims for near normal physiology of potential donors. After restoration of circulation after cardiac arrest, liver function can be assessed by biochemical and clotting profiles. Potential donors showing signs of progressive liver or multi-organ failure should be rejected.

While there are factors conducive to graft failure after transplantation (Table 1), the weight carried by each one of these has yet been determined. A marginal graft would have a better chance of survival only if it is transplanted to an otherwise healthy patient with liver failure. At which point the transplant becomes futile is difficult to determine. In places where deceased donor liver grafts are scarce and LDLT is not feasible for various reasons, a very low graft survival is beneficial enough to the patients. Nevertheless, on a societal level, such a marginal graft could have a much higher chance of survival if it is transplanted to a less ill patient. While graft condition and the severity of illness of the patient cannot be changed, optimization of the liver graft by resuscitation of the donor helps to maximize the chance of success, in terms of graft survival as well as recipient survival. A short CIT, prompt graft recovery from donors, and meticulous graft implantation all count.

\begin{tabular}{|l|l|}
\hline \multicolumn{2}{|l|}{ Table 1. Factors adversely affecting graft survival } \\
\hline Donor age & $>60$ years $[1,2,25]$ \\
\hline Graft size & Split or partial liver $[1]$ \\
\hline Ischemia & Donation after cardiac arrest $[1]$ \\
& CIT $>10 \mathrm{hr}[2,19,25]$ \\
\hline
\end{tabular}

This article is protected by copyright. All rights reserved. 


\begin{tabular}{|l|l|}
\hline & WIT > 40 min [2] \\
\hline Parenchymal & Fatty liver [19] \\
\hline Biochemical & Serum sodium [25] \\
\hline Stature & Weight [25] \\
& $\begin{array}{l}\text { Less height [1] } \\
\text { Body mass index [3] }\end{array}$ \\
\hline
\end{tabular}

\section{References}

[1] Feng S, Goodrich NP, Bragg-Gresham JL, Dykstra DM, Punch JD, DebRoy MA, et al. Characteristics associated with liver graft failure: the concept of a donor risk index. Am J Transplant 2006;6:783-790.

[2] Cameron AM, Ghobrial RM, Yersiz H, Farmer DG, Lipshutz GS, Gordon SA, et al. Optimal utilization of donor grafts with extended criteria: a single-center experience in over 1000 liver transplants. Ann Surg 2006;243:748-753; discussion 753-755.

[3] Bloom MB, Raza S, Bhakta A, Ewing T, Patel M, Ley EJ, et al. Impact of deceased organ donor demographics and critical care end points on liver transplantation and graft survival rates. J Am Coll Surg 2015;220:38-47.

[4] Wood KE, Becker BN, McCartney JG, D'Alessandro AM, Coursin DB. Care of the potential organ donor. N Engl J Med 2004;351:2730-2739.

[5] Power C, Rasko JE. Whither Prometheus' liver? Greek myth and the science of regeneration. Ann Intern Med 2008;149:421-426.

[6] Chan SC, Lo CM, Ng KK, Fan ST. Alleviating the burden of small-for-size graft in right liver

This article is protected by copyright. All rights reserved. 
living donor liver transplantation through accumulation of experience. Am J Transplant 2010;10:859-867.

[7] Imamura H, Kokudo N, Sugawara Y, Sano K, Kaneko J, Takayama T, et al. Pringle's maneuver and selective inflow occlusion in living donor liver hepatectomy. Liver Transpl 2004;10:771778.

[8] Selzner N, Rudiger H, Graf R, Clavien PA. Protective strategies against ischemic injury of the liver. Gastroenterology 2003;125:917-936.

[9] Hoyer DP, Paul A, Saner F, Gallinat A, Mathé Z, Treckmann JW, et al. Safely expanding the donor pool: Donors after brain death with history of temporary cardiac arrest. Liver Int 2015.

[10] Totsuka E, Fung JJ, Urakami A, Moras N, Ishii T, Takahashi K, et al. Influence of donor cardiopulmonary arrest in human liver transplantation: possible role of ischemic preconditioning. Hepatology 2000;31:577-580.

[11] DeOliveira ML, Graf R, Clavien PA. Ischemic preconditioning: promises from the laboratory to patients--sustained or disillusioned? Am J Transplant 2008;8:489-491.

[12] Azoulay D, Del Gaudio M, Andreani P, Ichai P, Sebag M, Adam R, et al. Effects of 10 minutes of ischemic preconditioning of the cadaveric liver on the graft's preservation and function: the ying and the yang. Ann Surg 2005;242:133-139.

[13] Jassem W, Fuggle SV, Cerundolo L, Heaton ND, Rela M. Ischemic preconditioning of cadaver donor livers protects allografts following transplantation. Transplantation 2006;81:169-174.

[14] Cescon M, Grazi GL, Grassi A, Ravaioli M, Vetrone G, Ercolani G, et al. Effect of ischemic preconditioning in whole liver transplantation from deceased donors. A pilot study. Liver Transpl 2006;12:628-635.

[15] Amador A, Grande L, Martí J, Deulofeu R, Miquel R, Solá A, et al. Ischemic pre-conditioning in deceased donor liver transplantation: a prospective randomized clinical trial. Am J Transplant This article is protected by copyright. All rights reserved. 
$2007 ; 7: 2180-2189$.

[16] Koneru B, Fisher A, He Y, Klein KM, Skurnick J, Wilson DJ, et al. Ischemic preconditioning in deceased donor liver transplantation: a prospective randomized clinical trial of safety and efficacy. Liver Transpl 2005;11:196-202.

[17] Koneru B, Shareef A, Dikdan G, Desai K, Klein KM, Peng B, et al. The ischemic preconditioning paradox in deceased donor liver transplantation-evidence from a prospective randomized single blind clinical trial. Am J Transplant 2007;7:2788-2796.

[18] Levesque E, Hoti E, Khalfallah M, Salloum C, Ricca L, Vibert E, et al. Impact of reversible cardiac arrest in the brain-dead organ donor on the outcome of adult liver transplantation. Liver Transpl 2011;17:1159-1166.

[19] Chu KK, Chan SC, Sharr WW, Chok KS, Dai WC, Lo CM. Low-volume deceased donor liver transplantation alongside a strong living donor liver transplantation service. World J Surg 2014;38:1522-1528.

[20] Mathur AK, Heimbach J, Steffick DE, Sonnenday CJ, Goodrich NP, Merion RM. Donation after cardiac death liver transplantation: predictors of outcome. Am J Transplant 2010;10:25122519.

[21] Chan SC, Lo CM, Liu CL, Fan ST. Resurgence of biliary cast syndrome. Liver Transpl $2005 ; 11: 242-243$

[22] Fondevila C, Hessheimer AJ, Flores E, Ruiz A, Mestres N, Calatayud D. Applicability and results of Maastricht type 2 donation after cardiac death liver transplantation. Am J Transplant 2012;12:162-170.

[23] Schaubel DE, Sima CS, Goodrich NP, Feng S, Merion RM. The survival benefit of deceased donor liver transplantation as a function of candidate disease severity and donor quality. Am J Transplant 2008;8:419-425.

This article is protected by copyright. All rights reserved. 
[24] Lo CM. Liver transplantation for acute liver failure: not too early but never too late. Liver Transpl 2008;14:1243-1244.

[25] Stey AM, Doucette J, Florman S, Emre S. Donor and recipient factors predicting time to graft failure following orthotopic liver transplantation: a transplant risk index. Transplant Proc $2013 ; 45: 2077-2082$.

This article is protected by copyright. All rights reserved. 